\title{
Natural History of Intra-abdominal Fluid Collections Following Pancreatic Surgery
}

\author{
Marek Sierzega • Piotr Kulig • Piotr Kolodziejczyk • \\ Jan Kulig
}

Received: 7 March 2013 / Accepted: 9 May 2013 / Published online: 29 May 2013

(C) 2013 The Author(s). This article is published with open access at Springerlink.com

\begin{abstract}
Background Little data are available for non-abscess abdominal fluid collections (AFCs) after pancreatic surgery and their clinical implications. We sought to analyze the natural history of such collections in a population of patients subject to routine postoperative imaging.

Methods From 1995 to 2011, 709 patients underwent pancreatic resections and routine postoperative monitoring with abdominal ultrasound according to a unit protocol. AFCs were classified as asymptomatic (no interventional treatment), symptomatic (need for percutaneous drainage of sterile, amylase-poor fluid), and pancreatic fistula (drainage of amylase-rich fluid).

Results Ninety-seven of 149 AFCs (65\%) were asymptomatic and resolved spontaneously after a median follow-up of 22 days (interquartile range, 9-52 days). Among 52 (35\%) AFCs requiring percutaneous drainage, there were 20 pancreatic fistulas and 32 symptomatic collections. A stepwise logistic regression model identified three factors associated with the need for interventional treatment, i.e., body mass index $\geq 25$ (odds ratio, 3.23; $95 \%$ confidence interval (CI), 1.32 to 7.91), pancreatic fistula (odds ratio, 2.93; $95 \%$ CI, 1.20 to 7.17), and biliary fistula (odds ratio, 3.92; $95 \%$ CI, 1.35 to 11.31 ). Conclusions One fourth of patients develop various types of non-abscess AFCs after pancreatic surgery. Around half of them are asymptomatic and resolve spontaneously.
\end{abstract}

Keywords Pancreaticoduodenectomy · Pancreatectomy · Distal pancreatectomy $\cdot$ Complications $\cdot$ Abdominal fluid collections

\section{Introduction}

The marked decrease in postoperative mortality reported over recent decades for pancreatic resections is not paralleled by significant changes in morbidity rates. ${ }^{1,2}$ Various types of fluid collections within the abdomen remain among the most common complications of pancreatic

Presented in part to the International Surgical Week ISW 2011, Yokohama, Japan, August 2011.

M. Sierzega $(\bowtie) \cdot$ P. Kulig $\cdot$ P. Kolodziejczyk $\cdot$ J. Kulig First Department of General and GI Surgery,

Jagiellonian University Medical College, 40 Kopernika Street,

31-501 Krakow, Poland

e-mail: marek.sierzega@uj.edu.pl surgery as no effective prophylaxis is available despite many technical and pharmacological attempts.

In more recent series, the incidence of intra-abdominal abscesses following pancreatic resections ranges from 6 to $11 \%{ }^{3-6}$ However, little is known about non-abscess abdominal fluid collections (AFCs). Such findings, as generally believed, are relatively common in the early postoperative course of patients subject to pancreatic surgery and often resolve spontaneously. ${ }^{7,8}$ Nevertheless, there is little evidence to support such claims as AFCs are rarely reported even in randomized clinical trials focused on the technical aspects of pancreatectomy., ${ }^{2,9-11}$ This is partly related to the retrospective design of most studies on complications associated with pancreatic surgery and lack of routine postoperative abdominal imaging in asymptomatic patients. Consequently, many aspects related to the natural history of AFCs remain to be clarified to provide information useful for clinical decision making in the early postoperative period. ${ }^{12-16}$

Since 1990, data of all patients undergoing pancreatic surgery at our academic tertiary surgical center have been 
documented prospectively in a computerized database. Moreover, all patients are subject to routine abdominal ultrasound (US) before drain removal and at follow-up visits. Such a unit protocol allows for early identification and monitoring of potential abdominal complications in otherwise asymptomatic patients. Given the paucity of published data on non-abscess abdominal collections after pancreatic surgery, the aim of this study was to analyze the natural history of AFCs and identify risk factors predicting the need for interventional treatment of such collections.

\section{Methods}

\section{Patients and Perioperative Care}

An electronic database of all patients undergoing pancreatic resections between 1990 and 2011 at our academic tertiary surgical center was reviewed. All relevant data, including demographics, clinical findings, details of surgical procedures, and histopathological parameters, were collected prospectively using a standardized form. The present study was limited to the period of 1995 through 2011 when results of routine imaging tests were incorporated in the database. The study was approved by the Bioethics Committee of Jagiellonian University.

All procedures were carried out by four senior consultant surgeons experienced in pancreatobiliary surgery and using a similar technique of dissection. Technical variations of pancreatic resections, e.g., pylorus preservation, types of pancreatic anastomosis, extent of lymphadenectomy, were performed according to the surgeons' preferences and classified as defined by the recent guidelines. ${ }^{17}$ Abdominal drains were routinely used and typically removed on postoperative day (POD) 4 to 5 if daily drainage was $<50 \mathrm{ml}$ of unsuspected effluent with low amylase content. Patients received perioperative antibiotic prophylaxis, most commonly first-generation and second-generation cephalosporins, and low-molecular-weight heparin was used to minimize the risk of thromboembolic events. Postoperative analgesia was provided by epidural infusion of bupivacaine and fentanyl combined with intravenous morphine chloride and nonsteroidal anti-inflammatory drugs as required. Prophylactic octreotide was used under surgeon's discretion in a dose of $100 \mu \mathrm{g}$ s.c. starting before surgery and followed up every $8 \mathrm{~h}$ for 5 days. As a unit protocol, abdominal US was carried out in all patients prior to drain removal (POD 4 to 5) and immediately before discharge. US and/or computed tomography (CT) were also performed in any patient with laboratory abnormalities (raised total white blood cell [WBC] count and increased C-reactive protein or procalcitonin levels), fever, or abdominal discomfort. Follow-up examinations were carried out as clinically required and included routine US in all patients 1 to 2 weeks after discharge.

\section{Postoperative Complications}

All deviations from the normal postoperative course were recorded and prospectively verified by a pancreatic research fellow (M.S.). Major surgical complications were classified according to the current definitions, i.e., postoperative pancreatic fistula (POPF: drain output of any measurable volume of fluid on or after POD 3 with an amylase content greater than three times the serum amylase activity), ${ }^{18}$ delayed gastric emptying (inability to return to a standard diet by the end of the first postoperative week with prolonged nasogastric intubation), ${ }^{19}$ postpancreatectomy hemorrhage (evidence of blood loss from drains, nasogastric tube, or on ultrasonography associated with a decrease in hemoglobin concentration). ${ }^{20}$ Bile leak was defined as bilious abdominal drainage confirmed by a contrast study through an abdominal drain or cholangiography. ${ }^{21}$ Abdominal abscess was defined as collection of fluid diagnosed with US/CT and positive cultures obtained by percutaneous drainage or at reoperation, regardless of amylase content. ${ }^{22}$ Non-abscess AFC was defined as a collection of fluid measuring $\geq 3 \mathrm{~cm}$ in diameter demonstrated by transabdominal US or CT scan. ${ }^{9}$ Asymptomatic AFCs were followed up with US/CT until spontaneous resolution. AFCs associated with clinical (abdominal discomfort and fever) or laboratory abnormalities (high WBC count and increased Creactive protein or procalcitonin levels) were drained under US guidance, and aspirated fluid was sent for culture and amylase assay. Sterile collections of amylase-rich fluid were classified as POPFs and those with low amylase content were reported as symptomatic AFCs. Other surgical and medical complications were defined as previously described. ${ }^{23}$ Operative mortality was defined as any in-hospital death or death occurring within 30 days from surgery.

\section{Statistical Analysis}

The differences in proportions between groups were evaluated using the chi-square test, and the Mann-Whitney $U$ test was used to detect differences in quantitative variables. Potential risk factors for AFCs requiring interventional treatment were evaluated by univariate analysis using cross-tabulations and a stepwise logistic regression model. The following factors were analyzed: sex, age ( $\leq 65$ vs $>65$ years), American Society of Anesthesiology (ASA) physical status (1-2 vs 3-4), diagnosis (benign vs malignant), preexisting diseases (no vs yes), body mass index (BMI $<25$ vs $\geq 25)$, preoperative body weight loss ( $<10$ vs $\geq 10 \%$ ), preoperative albumin level ( $<35 \mathrm{vs} \geq 35 \mathrm{~g} / \mathrm{dl}$ ), preoperative bilirubin level ( $<30$ vs $\geq 30 \mu \mathrm{mol} / \mathrm{L})$, preoperative biliary drainage (no vs yes), type of resection (pancreaticoduodenectomy, distal pancreatectomy, total pancreatectomy, and other), lymph node 
dissection (standard vs extended), operative time $(\leq 300$ vs $>300 \mathrm{~min}$ ), use of somatostatin analogs (no vs yes), need for autologous blood transfusion (no vs yes), pancreatic gland texture (hard vs soft), pancreatic fistula (no vs yes), biliary fistula (no vs yes), and enteric fistula (no vs yes). Significance level $(P)<0.05$ was considered statistically significant in a two-tailed analysis. Statistical analysis was performed using the IBM SPSS v.20 (SPSS Inc., Chicago, IL, USA) software package.

\section{Results}

\section{Postoperative Complications}

A total of 718 patients who underwent pancreatic resections were identified in the database between 1995 and 2011. Details of routine US imaging were available in 709 cases, and this group constituted the final study population (Table 1). There were 373 males and 336 females, with a

Table 1 Patient demographics and clinicopathological parameters

\begin{tabular}{ll}
\hline Age, years, median (IQR) & $59(48-66)$ \\
Female/male, $n(\%)$ & $336(47) / 373(53)$ \\
Diagnosis, $n$ (\%) & \\
Pancreatic cancer & $300(42)$ \\
Ampullary cancer & $150(21)$ \\
Chronic pancreatitis & $93(13)$ \\
Endocrine tumors & $55(8)$ \\
Cystic tumor & $36(5)$ \\
Miscellaneous & $75(11)$ \\
Comorbidities, $n(\%)$ & \\
Circulatory & \\
Pulmonary & $173(24)$ \\
Diabetes mellitus & $28(4)$ \\
ASA physical status (1-2/3-4) & $97(14)$ \\
BMI, median (IQR) & $489 / 220$ \\
Serum albumin, g/dl, median (IQR) & $23.5(21.2-26.5)$ \\
Serum bilirubin, $\mu$ mol/L, median (IQR) & $40(37-44)$ \\
Preoperative biliary drainage, $n(\%)$ & $15(8-41)$ \\
Procedure, $n$ (\%) & $101(14)$ \\
Pancreaticoduodenectomy (PD) & \\
Pylorus-preserving PD & $253(36)$ \\
Distal pancreatectomy & $153(22)$ \\
Total pancreatectomy & $188(27)$ \\
Segmental resection & $85(12)$ \\
Enucleation & $11(2)$ \\
\hline & $19(3)$ \\
\hline
\end{tabular}

Values in parentheses are percentages (unless indicated)

$I Q R$ interquartile range

${ }^{\mathrm{a}}$ Ischemic heart disease, arrhythmia, previous myocardial infarction, and coronary artery disease

${ }^{\mathrm{b}}$ Asthma and chronic obstructive pulmonary disease median age of 59 years (range, 21 to 83 years). No neoadjuvant therapy was used for patients with preoperatively verified malignancy. The overall morbidity rate was $46 \%$ (326 of 709 patients), with surgical and nonsurgical complications diagnosed in 31 and $27 \%$ of patients, respectively (Table 2). Reoperation was required in 57 (8\%) cases, including abdominal abscess $(n=24)$, abdominal bleeding $(n=22)$, wound dehiscence $(n=6)$, and other $(n=5)$. The median postoperative hospital stay was 22 days (interquartile range (IQR), 14-34 days) and was significantly $(P<0.001)$ longer in patients who developed complications (median, 28 days; IQR, 18-40 days) than for uneventful recovery (median, 12 days; IQR, 10-15 days). Thirty-one (4\%) patients died postoperatively.

\section{Abdominal Fluid Collections}

There were 149 (21\%) non-abscess AFCs, including 135 adjacent to the pancreatic remnant or in the bed of the resected pancreas and 14 distant collections. The median time from surgery to the diagnosis of AFCs was 7 days (IQR, 5-11 days; Fig. 1), and their median diameter was $6 \mathrm{~cm}$ (IQR, $4.5-7.0 \mathrm{~cm}$ ).

Table 2 Morbidity and mortality rates in 709 patients

\begin{tabular}{ll}
\hline Complications & No. (percent) of patients \\
\hline Any complication & $326(46)$ \\
Surgical complications & $219(31)$ \\
Abdominal fluid collection & $149(21)$ \\
Pancreatic fistula & $140(20)$ \\
Delayed gastric emptying & $60(8)$ \\
Wound infection & $54(8)$ \\
Intra-abdominal abscess & $43(6)$ \\
Abdominal bleeding & $31(4)$ \\
Enteric fistula & $21(3)$ \\
Biliary fistula & $17(2)$ \\
Gastrointestinal bleeding & $12(2)$ \\
Acute pancreatitis & $14(2)$ \\
Wound dehiscence & $6(1)$ \\
Ileus & $3(1)$ \\
Nonsurgical complications & $188(27)$ \\
Pneumonia & $148(21)$ \\
Sepsis & $47(7)$ \\
Pulmonary embolism & $35(5)$ \\
Cardiocirculatory failure & $32(5)$ \\
Renal failure & $28(4)$ \\
Urinary infection & $23(3)$ \\
Liver failure & $18(3)$ \\
Thrombophlebitis & $7(1)$ \\
Death & $31(4)$ \\
Reoperation & $57(8)$ \\
\hline
\end{tabular}


Fig. 1 Time elapsed from surgery to the diagnosis of AFC

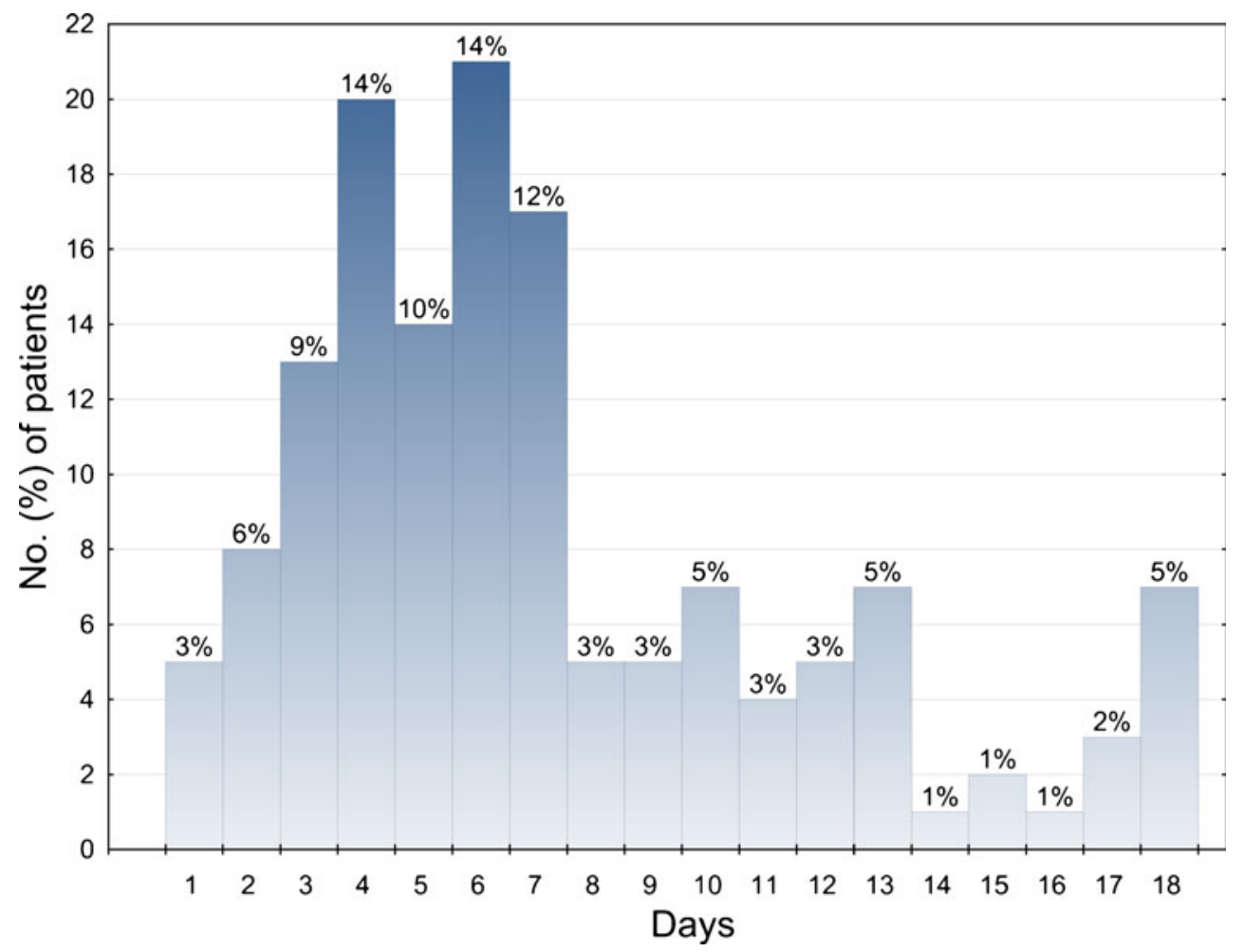

The proportion of patients diagnosed with early $(\leq \mathrm{POD} 7)$ and late (after POD 7) AFCs was similar for symptomatic (50 vs $50 \%$ ) and asymptomatic (55 vs $45 \%$ ) collections (Fig. 2). Collections defined as POPF were more common in the early postoperative period (70 vs $30 \%$ ), but the difference was statistically insignificant $(P=0.163)$. The median time to drain removal was 8 days (IQR, 5-12 days) and was significantly $(P=0.010)$ longer for patients with AFCs (14 days; IQR, 10-24 days) than

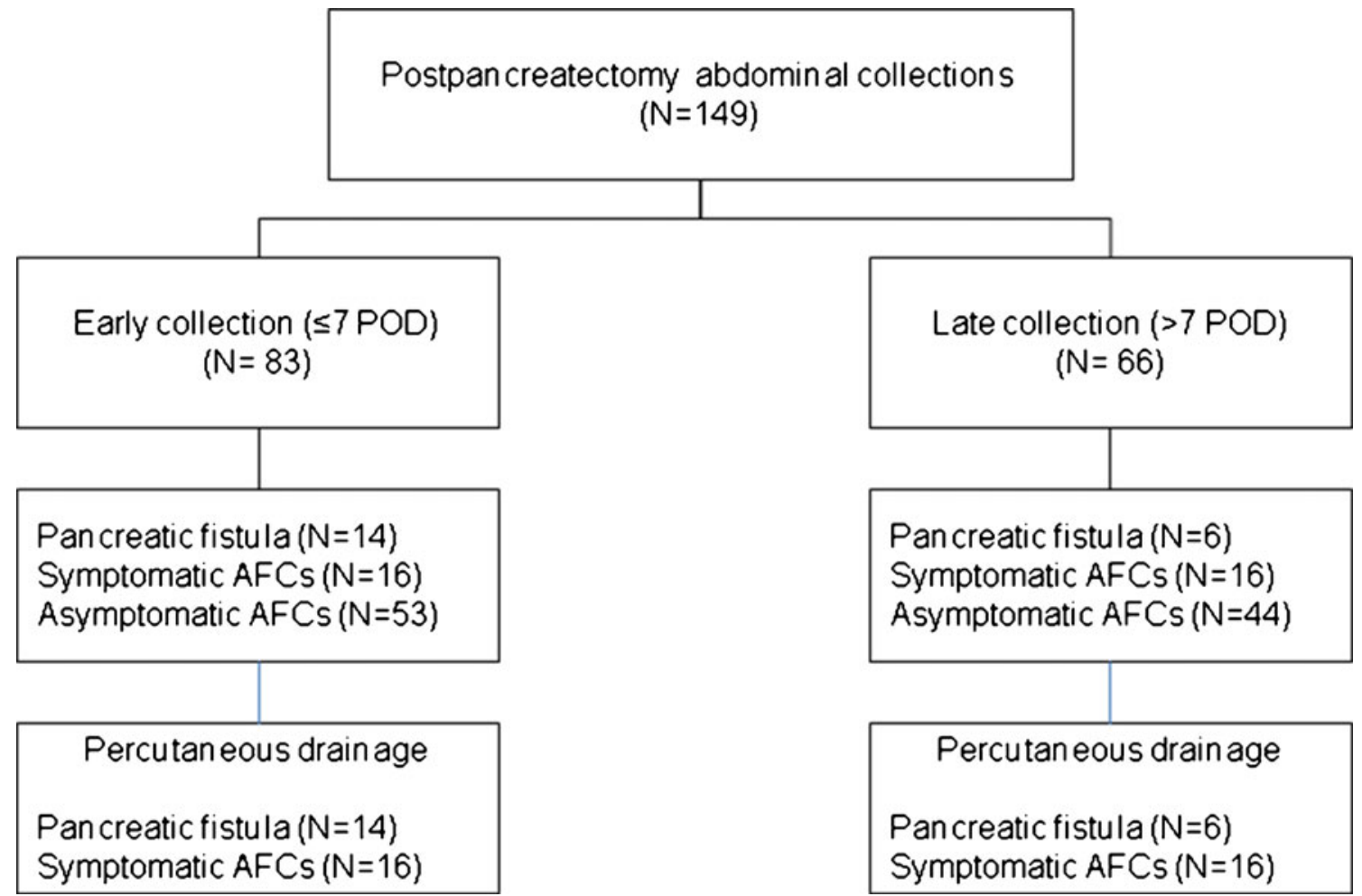

Fig. 2 Types of AFCs in relation to time. $P O D$ postoperative day 
without collections (5 days; IQR, 4-8 days). The proportion of patients who develop AFCs after drain removal was higher for collections defined as symptomatic (53\%) and POPF (75\%). However, asymptomatic collections were diagnosed more commonly before drain removal (59\%). Ninety-seven of 149 AFCs (65\%) were asymptomatic and resolved spontaneously after a median follow-up of 22 days (IQR, 9-52 days). Fifty-two (35\%) AFCs required percutaneous drainage after a median time from diagnosis of 8 days (IQR, 4-19 days). The median time from drainage to resolution of AFCs was 25 days (IQR, 6-78 days). Four patients required additional percutaneous interventions for new or recurrent fluid collections, and five were reoperated on due to persistent symptomatic AFCs. There were no drainagerelated complications. Hospital readmission related to collection was required in 27 patients (4\%) (Table 3).

Risk Factors for Fluid Collections Requiring Interventional Treatment

Univariate analysis of potential risk factors associated with the need for percutaneous drainage of AFCs is summarized in Table 4. Subsequent regression analysis (Table 5) of those variables that significantly affected the rate of interventional treatment in the univariate analysis identified three factors increasing the risk for drainage, i.e., BMI $\geq 25$ (odds ratio, 3.23 ; $95 \%$ confidence interval (CI), 1.32 to 7.91 ), pancreatic fistula (odds ratio, 2.93; $95 \% \mathrm{CI}, 1.20$ to 7.17 ), and biliary fistula (odds ratio, 3.92; $95 \% \mathrm{CI}, 1.35$ to 11.31 ).

\section{Discussion}

Surgical complications associated with pancreatic surgery have gained much attention over the recent years. Various aspects of POPF, delayed gastric emptying, abdominal bleeding, and abscesses were extensively analyzed, including recommendations for appropriate diagnosis and severity assessment. ${ }^{18-20}$ In contrast, little data are available for asymptomatic non-abscess AFCs and their clinical implications. Therefore, we sought to analyze the natural history of such collections in a population of patients subject to routine postoperative imaging. This study demonstrated that about $14 \%$ of patients after pancreatic resections developed transient AFCs that eventually resolved spontaneously without any intervention and a further $8 \%$ required percutaneous drainage for symptomatic collections. The need for percutaneous drainage was significantly increased among patients with high BMI and by coexisting pancreatic or biliary fistula.

Previous reports suggested that the incidence of AFCs varies from 4 to $30 \%{ }^{13,24-28}$ However, such numbers derived from retrospective studies are inherently biased by the fact that imaging tests are carried out only in patients with symptoms suggestive of intra-abdominal complications. Only a few studies provided some limited data from prospective observations. In the study of Bassi et al. using routine US imaging, 17 of $114(15 \%)$ patients were diagnosed with fluid collections $<5 \mathrm{~cm}$ in diameter on POD 3 after pancreaticoduodenectomy or distal pancreatectomy. ${ }^{9}$ In another report, 30 of $50(60 \%)$ patients subject to pancreaticoduodenectomy with a soft pancreas had AFCs on POD 7 diagnosed with routine CT scans. ${ }^{29}$ Nevertheless, neither of these reports provided information on the actual nature of such collections or their natural history. In the present study, 97 of 709 (14\%) patients monitored with routine postoperative US developed asymptomatic AFCs that regressed spontaneously after a median follow-up of 22 days. Another $52(8 \%)$ patients had fluid collections requiring percutaneous drainage, and the need for interventional treatment was significantly associated with high BMI, pancreatic fistula, and biliary fistula with odds ratios of about 3 .

The incidence rate of intra-abdominal collections associated with POPF ranges from 20 to $81 \%$ and is markedly higher in patients with fistula grades B and C. ${ }^{30-33}$ In this study, the proportion of asymptomatic collections was similar in patients with and without pancreatic fistula (14 vs $13 \%, P=0.816$ ), and the median time to their resolution was

Table 3 Type of abdominal collections by surgical procedure

\begin{tabular}{|c|c|c|c|c|c|c|}
\hline & $\begin{array}{l}\text { Pancreaticoduodenectomy } \\
(n=406)\end{array}$ & $\begin{array}{l}\text { Distal pancreatectomy } \\
(n=188)\end{array}$ & $\begin{array}{l}\text { Total } \\
\text { pancreatectomy } \\
(n=85)\end{array}$ & $\begin{array}{l}\text { Segmental resection or } \\
\text { enucleation }(n=30)\end{array}$ & Total $(n=709)$ & $P$ value $^{\mathrm{a}}$ \\
\hline Abscess & $24(6)$ & $9(5)$ & $7(8)$ & $3(10)$ & $43(6)$ & 0.552 \\
\hline Pancreatic fistula (POPF) & $15(4)$ & $3(2)$ & $0(0)$ & $2(7)$ & $20(3)$ & 0.031 \\
\hline Symptomatic AFCs & $16(4)$ & $11(6)$ & $3(4)$ & $2(7)$ & $32(5)$ & 0.820 \\
\hline Asymptomatic AFCs & $50(12)$ & $34(18)$ & $10(12)$ & $3(10)$ & 97 (14) & 0.366 \\
\hline
\end{tabular}

Values in parentheses are percentages

$P O P F$ postoperative pancreatic fistula, $A F C s$ abdominal fluid collections

${ }^{\mathrm{a}}$ Chi-square test 
Table 4 Univariate analysis of risk factors for non-abscess abdominal collections requiring percutaneous drainage (chi-square test)

\begin{tabular}{|c|c|c|c|c|c|c|c|}
\hline & & & & & & & \\
\hline Factor & Abdominal $\mathrm{fl}$ & d collections & uiring & Factor & $\begin{array}{l}\text { Abdominal } \mathrm{f} \\
\text { drainage }\end{array}$ & d collections $\mathrm{r}$ & uiring \\
\hline & & & & & Yes $(n=52)$ & No $(n=97)$ & $P$ value \\
\hline & Yes $(n=52)$ & No $(n=97)$ & $P$ value & & & & \\
\hline Age (years) & & & 0.944 & No & $30(58)$ & $77(79)$ & \\
\hline$\leq 65$ & $41(79)$ & $76(78)$ & & Yes & $22(42)$ & $20(21)$ & \\
\hline$>65$ & $11(21)$ & $21(22)$ & & Biliary fistula & & & 0.006 \\
\hline Gender & & & 0.496 & No & $44(85)$ & $94(97)$ & \\
\hline Female & $25(48)$ & $41(42)$ & & Yes & $8(15)$ & $3(3)$ & \\
\hline Male & $27(52)$ & $56(58)$ & & Enteric fistula & & & 0.477 \\
\hline Diagnosis & & & 0.716 & No & $51(98)$ & $93(96)$ & \\
\hline Benign & $12(23)$ & $25(26)$ & & Yes & $1(2)$ & $4(4)$ & \\
\hline
\end{tabular}

Malignant

$40(77)$

No

$23(44) \quad 41(42)$

Yes

$29(56)$

ASA physical status

$56(58)$

1 or 2

$37(71) \quad 67(69)$

3 or 4

$15(29)$

BMI

$<25$

$31(60)$

$30(31)$

$\geq 25$

Body weight loss $>10 \%$

No

Yes

Albumin, g/dl

$\leq 35$

$>35$

Bilirubin, $\mu \mathrm{mol} / \mathrm{L}$

$\leq 30$

$>30$

Preoperative biliary drainage

No

Yes

Procedure

Pancreaticoduodenectomy

Distal pancreatectomy

Total pancreatectomy

Other

Operative time $(\mathrm{min})$

$\leq 300$

$>300$

Lymph node dissection

Standard

Extended

Pancreatic gland texture

Hard

Soft

Somatostatin use

No

Yes

Need for blood transfusion

No

Yes
$21(40)$

37 (71)

15 (29)

9 (17)

$43(83)$

44 (85)

8 (15)

39 (75)

13 (25)

$31(60)$

14 (27)

3 (6)

4 (7)

29 (56)

23 (44)

$34(65)$

18 (35)

$11(21)$

41 (79)

17 (33)

$35(67)$

19 (37)

33 (63)
$73(75)$

24 (25)

$56(58)$

41 (42)

12 (12)

$85(88)$

0.357

76 (78)

$21(22)$

$72(74)$

25 (26)

$50(52)$

34 (35)

10 (10)

$3(3)$

45 (46)

52 (54)

$56(58)$

$41(42)$

$13(13)$

84 (87)

45 (46)

52 (54)

$50(52)$

$47(48)$

0.275

0.362
0.350

Table 4 (continued)

comparable ( 17 vs 23 days, $P=0.668$ ). However, the proportion of patients with symptomatic collections requiring drainage was significantly higher ( 14 vs $6 \%, P<0.001)$, and all of them were verified as POPF due to high amylase content. This suggests that asymptomatic AFCs do not always require interventional treatment in a patient with POPF. Such an opinion is supported by observations made by Pratt et al. who reported percutaneous drainage only in 14 of 34 patients with POPF grades B and C and fluid collections after various pancreatic resections. ${ }^{33}$

Data for the impact of biliary fistulas on abdominal complications after pancreatic surgery are scarce. The largest study, of Burkhart et al., reported hepaticojejunostomy leaks after pancreaticoduodenectomy in 16 of 715 patients $(2.2 \%){ }^{21}$ Leaks were significantly associated with pancreatic fistula ( 50 vs $12 \%, P<0.001)$, wound infection ( 38 vs $8 \%, P=0.003$ ), delayed gastric emptying ( 31 vs $10 \%, P=$ 0.036 ), and sepsis ( 31 vs $3 \%, P<0.001)$. However, the authors provided no information about abdominal collections. Another retrospective analysis of 149 patients subject to pancreatoduodenectomy revealed that early ( $\leq 7$ days postoperatively) collections were associated with either

Table 5 Multivariable logistic regression analysis of risk factors for non-abscess abdominal collections requiring percutaneous drainage

\begin{tabular}{lll}
\hline Factor & Odds ratio $(95 \% \mathrm{CI})$ & $P$ value \\
\hline BMI & & \\
$<25$ & Reference & 0.010 \\
$\geq 25$ & $3.23(1.32-7.91)$ & \\
Pancreatic fistula & & 0.018 \\
No & Reference & \\
Yes & $2.93(1.20-7.17)$ & \\
Biliary fistula & & 0.012 \\
No & Reference & \\
Yes & $3.92(1.35-11.31)$ & \\
\hline
\end{tabular}


pancreatic anastomotic or biliary leaks. ${ }^{13}$ Nevertheless, any formal analysis of such an association for biliary fistula was not possible due to very small sample size, i.e., only three patients with biliary leaks.

The only preoperative factor significantly associated in this study with the need for interventional treatment of AFCs was BMI $\geq 25$. A supplementary analysis failed to confirm such a relationship with other abdominal complications, including asymptomatic AFCs and POPF (data not shown). This correlation is somehow controversial not only for pancreatic surgery but also for other types of abdominal surgery. ${ }^{34}$ A recent metaanalysis of 17 studies and a total of 4,045 patients showed no definitive detrimental effects of overweight/obesity on postoperative outcomes, with only four studies reporting higher rates of POPF (odds ratio range, 1.6-4.2). ${ }^{35}$ In fact, even those studies suggesting increased morbidity rates among patients with high BMI provided no detailed data necessary to establish a potential association between overweight and various types of abdominal collections.

The present analysis has some inherent limitations. First, we used abdominal US for screening of asymptomatic patients, and this could underestimate rates of fluid collections compared to CT. The operator-dependent characteristics of such imaging must be taken into account, though; all examinations were carried out by surgeons acquainted with US assessment of patients following abdominal surgery and a caseload of about 1,000 per year. Second, asymptomatic collections were not verified by percutaneous aspiration, and this may raise the question about their actual nature. However, such collections were evenly distributed among patients with pancreatic, biliary, and enteric fistulas, and time to their resolution was not affected by these complications. This provides some evidence that asymptomatic collections were most probably unrelated to other abdominal complications. Third, we could not examine the correlation between drain removal and fluid collections as drains were routinely removed on POD 4 to 5 after US excluded potential abdominal complications. Therefore, prolonged drainage in our case was a consequence of abnormal recovery based on US or clinical findings. Some previous studies suggested that early drain removal (POD 3 or 4 ) is superior to prolonged drainage (POD 5 or 8 ) in terms of reduced rates of abdominal complications. ${ }^{9,11}$ Similar benefits were demonstrated by a retrospective cohort study in patients without routine abdominal drainage. ${ }^{36}$ However, the latter group published earlier the only existing randomized clinical trial on routine intraperitoneal drainage after pancreatic resections and failed to demonstrate significant differences in the incidence of abdominal collections ( 6.8 vs $2.2 \%$ in drained and not drained group, respectively) or abscesses $(6.8$ vs $6.6 \%) .{ }^{10}$ Therefore, the question of whether routine drainage increases the risk of abdominal collections in pancreatic surgery remains unanswered.

\section{Conclusion}

In conclusion, this study demonstrated that approximately one fourth of patients develop various types of AFCs after pancreatic surgery. About half of them are asymptomatic and resolve spontaneously. However, collections associated with pancreatic and biliary fistulas, as well as those in patients with high BMI, are likely to require interventional treatment.

\section{Conflict of Interest None.}

Open Access This article is distributed under the terms of the Creative Commons Attribution License which permits any use, distribution, and reproduction in any medium, provided the original author(s) and the source are credited.

\section{References}

1. Berberat PO, Friess H, Kleeff J, Uhl W, Buchler MW. Prevention and treatment of complications in pancreatic cancer surgery. Dig Surg 1999;16:327-336.

2. Halloran CM, Ghaneh P, Bosonnet L, Hartley MN, Sutton R, Neoptolemos JP. Complications of pancreatic cancer resection. Dig Surg 2002;19:138-146.

3. Cameron JL, Riall TS, Coleman J, Belcher KA. One thousand consecutive pancreaticoduodenectomies. Ann Surg 2006;244:10-15.

4. Fernandez-del Castillo C, Morales-Oyarvide V, McGrath D, Wargo JA, Ferrone CR, Thayer SP, Lillemoe KD, Warshaw AL. Evolution of the Whipple procedure at the Massachusetts General Hospital. Surgery 2012;152:S56-S63.

5. Frymerman AS, Schuld J, Ziehen P, Kollmar O, Justinger C, Merai M, Richter S, Schilling MK, Moussavian MR. Impact of postoperative pancreatic fistula on surgical outcome - the need for a classification-driven risk management. J Gastrointest Surg 2010;14:711-718.

6. Kelly KJ, Greenblatt DY, Wan Y, Rettammel RJ, Winslow E, Cho CS, Weber SM. Risk stratification for distal pancreatectomy utilizing ACS-NSQIP: preoperative factors predict morbidity and mortality. J Gastrointest Surg 2011;15:250-259, discussion 259-261.

7. Yeo CJ. Management of complications following pancreaticoduodenectomy. Surg Clin North Am 1995;75:913-924.

8. Gervais DA, Fernandez-del Castillo C, O'Neill MJ, Hahn PF, Mueller PR. Complications after pancreatoduodenectomy: imaging and imaging-guided interventional procedures. Radiographics 2001;21:673-690.

9. Bassi C, Molinari E, Malleo G, Crippa S, Butturini G, Salvia R, Talamini G, Pederzoli P. Early versus late drain removal after standard pancreatic resections: results of a prospective randomized trial. Ann Surg 2010;252:207-214.

10. Conlon KC, Labow D, Leung D, Smith A, Jarnagin W, Coit DG, Merchant N, Brennan MF. Prospective randomized clinical trial of the value of intraperitoneal drainage after pancreatic resection. Ann Surg 2001;234:487-493.

11. Kawai M, Tani M, Terasawa H, Ina S, Hirono S, Nishioka R, Miyazawa M, Uchiyama K, Yamaue H. Early removal of prophylactic drains reduces the risk of intra-abdominal infections in patients with pancreatic head resection: prospective study for 104 consecutive patients. Ann Surg 2006;244:1-7.

12. OS AA, LaBerge JM, Gordon RL, Wilson MW, Mulvihill SJ, Way LW, Kerlan RK. Percutaneous management of abscess and fistula 
following pancreaticoduodenectomy. Cardiovasc Intervent Radiol 1999;22:25-28.

13. Barreto G, D'Souza MA, Shukla PJ, Shrikhande SV. The gray zone between postpancreaticoduodenectomy collections and pancreatic fistula. Pancreas 2008;37:422-425.

14. Sohn TA, Yeo CJ, Cameron JL, Geschwind JF, Mitchell SE, Venbrux AC, Lillemoe KD. Pancreaticoduodenectomy: role of interventional radiologists in managing patients and complications. J Gastrointest Surg 2003;7:209-219.

15. Zink SI, Soloff EV, White RR, Clary BM, Tyler DS, Pappas TN, Paulson EK. Pancreaticoduodenectomy: frequency and outcome of post-operative imaging-guided percutaneous drainage. Abdom Imaging 2009;34:767-771.

16. Vin Y, Sima CS, Getrajdman GI, Brown KT, Covey A, Brennan MF, Allen PJ. Management and outcomes of postpancreatectomy fistula, leak, and abscess: results of 908 patients resected at a single institution between 2000 and 2005. J Am Coll Surg 2008;207:490-498.

17. Pedrazzoli S, Beger HG, Obertop H, Andren-Sandberg A, Fernandez-Cruz L, Henne-Bruns D, Luttges J, Neoptolemos JP. A surgical and pathological based classification of resective treatment of pancreatic cancer. Summary of an international workshop on surgical procedures in pancreatic cancer. Dig Surg 1999;16:337-345.

18. Bassi C, Dervenis C, Butturini G, Fingerhut A, Yeo C, Izbicki J, Neoptolemos J, Sarr M, Traverso W, Buchler M. Postoperative pancreatic fistula: an international study group (ISGPF) definition. Surgery $2005 ; 138: 8-13$.

19. Wente MN, Bassi C, Dervenis C, Fingerhut A, Gouma DJ, Izbicki JR, Neoptolemos JP, Padbury RT, Sarr MG, Traverso LW, Yeo CJ, Buchler MW. Delayed gastric emptying (DGE) after pancreatic surgery: a suggested definition by the International Study Group of Pancreatic Surgery (ISGPS). Surgery 2007;142:761-768.

20. Wente MN, Veit JA, Bassi C, Dervenis C, Fingerhut A, Gouma DJ, Izbicki JR, Neoptolemos JP, Padbury RT, Sarr MG, Yeo CJ, Buchler MW. Postpancreatectomy hemorrhage (PPH): an International Study Group of Pancreatic Surgery (ISGPS) definition. Surgery 2007;142:20-25.

21. Burkhart RA, Relles D, Pineda DM, Gabale S, Sauter PK, Rosato EL, Koniaris LG, Lavu H, Kennedy EP, Yeo CJ, Winter JM. Defining treatment and outcomes of hepaticojejunostomy failure following pancreaticoduodenectomy. J Gastrointest Surg 2013;17:451-460.

22. Strasberg SM, Linehan DC, Clavien PA, Barkun JS. Proposal for definition and severity grading of pancreatic anastomosis failure and pancreatic occlusion failure. Surgery 2007;141:420-426.

23. Klek S, Kulig J, Sierzega M, Szybinski P, Szczepanek K, Kubisz A, Kowalczyk T, Gach T, Pach R, Szczepanik AM. The impact of immunostimulating nutrition on infectious complications after upper gastrointestinal surgery: a prospective, randomized, clinical trial. Ann Surg 2008;248:212-220.
24. Bassi C, Falconi M, Salvia R, Mascetta G, Molinari E, Pederzoli P. Management of complications after pancreaticoduodenectomy in a high volume centre: results on 150 consecutive patients. Dig Surg 2001;18:453-457.

25. Lermite E, Pessaux P, Brehant O, Teyssedou C, Pelletier I, Etienne S, Arnaud JP. Risk factors of pancreatic fistula and delayed gastric emptying after pancreaticoduodenectomy with pancreaticogastrostomy. J Am Coll Surg 2007;204:588-596.

26. Malleo G, Crippa S, Butturini G, Salvia R, Partelli S, Rossini R, Bacchion M, Pederzoli P, Bassi C. Delayed gastric emptying after pylorus-preserving pancreaticoduodenectomy: validation of International Study Group of Pancreatic Surgery classification and analysis of risk factors. HPB (Oxford) 2010;12:610-618.

27. Mortele KJ, Lemmerling M, de Hemptinne B, De Vos M, De Bock G, Kunnen M. Postoperative findings following the Whipple procedure: determination of prevalence and morphologic abdominal CT features. Eur Radiol 2000;10:123-128.

28. Pisters PW, Hudec WA, Hess KR, Lee JE, Vauthey JN, Lahoti S, Raijman I, Evans DB. Effect of preoperative biliary decompression on pancreaticoduodenectomy-associated morbidity in 300 consecutive patients. Ann Surg 2001;234:47-55.

29. Bruno O, Brancatelli G, Sauvanet A, Vullierme MP, Barrau V, Vilgrain V. Utility of CT in the diagnosis of pancreatic fistula after pancreaticoduodenectomy in patients with soft pancreas. AJR Am J Roentgenol 2009;193:W175-W180.

30. Cullen JJ, Sarr MG, Ilstrup DM. Pancreatic anastomotic leak after pancreaticoduodenectomy: incidence, significance, and management. Am J Surg 1994;168:295-298.

31. Lin JW, Cameron JL, Yeo CJ, Riall TS, Lillemoe KD. Risk factors and outcomes in postpancreaticoduodenectomy pancreaticocutaneous fistula. J Gastrointest Surg 2004;8:951-959.

32. Munoz-Bongrand N, Sauvanet A, Denys A, Sibert A, Vilgrain V, Belghiti J. Conservative management of pancreatic fistula after pancreaticoduodenectomy with pancreaticogastrostomy. J Am Coll Surg 2004;199:198-203.

33. Pratt W, Maithel SK, Vanounou T, Callery MP, Vollmer CM, Jr. Postoperative pancreatic fistulas are not equivalent after proximal, distal, and central pancreatectomy. J Gastrointest Surg 2006;10:1264-1278.

34. Doyle SL, Lysaght J, Reynolds JV. Obesity and post-operative complications in patients undergoing non-bariatric surgery. Obes Rev 2010;11:875-886.

35. Ramsey AM, Martin RC. Body mass index and outcomes from pancreatic resection: a review and meta-analysis. J Gastrointest Surg 2011;15:1633-1642.

36. Correa-Gallego C, Brennan MF, D'Angelica M, Fong Y, Dematteo RP, Kingham TP, Jarnagin WR, Allen PJ. Operative drainage following pancreatic resection: analysis of 1122 patients resected over 5 years at a single institution. Ann Surg 2013. doi:10.1097/ SLA.0b013e3182813806 